\title{
Relações interpessoais em comunidades virtuais de aprendizagem
}

\section{Interpersonal relationships in virtual learning communities}

\section{Resumo:}

Esse estudo teve como objetivo investigar as relações interpessoais em comunidades virtuais de aprendizagem (CVA). A pesquisa foi realizada com 18 alunos do 30 semestre do curso de Graduação semipresencial em Letras-Português, da Universidade Federal do Ceará, uma parceria com a Universidade Aberta do Brasil, no semestre 2008/2. Utilizou-se como método de pesquisa o etnográfico e os princípios da etnografia virtual. Nos resultados, foram elencadas quatro subcategorias: amizade, informalidade, incentivo e agradecimento. Os resultados obtidos se manifestaram especificamente nos espaços formais de aprendizagem.

Palavras-Chaves: Relações Interpessoais. Educação a Distância. Comunidades Virtuais de Aprendizagem.

\section{Abstract:}

This study aims at investigating the interpersonal relationships in virtual learning communities (VLC). The research was performed with 18 students from the 3rd semester in the Languages - Portuguese semipresential graduation course in a Federal University of Ceara, a partnership with the Open University of Brazil (Universidade Aberta do Brasil), during the second semester of 2008. The ethnographic research method and virtual ethnography were applied. Four subcategories were assembled in the results: friendship, informality, incentive and gratefulness. The results obtained were manifested specifically in formal learning areas.

Keywords: Interpersonal Relationships. Distance Education. Virtual Learning Communities.

VENTURA, Paula Patrícia Barbosa. Relações Interpessoais em Comunidades Virtuais de Aprendizagem. Informática na Educação: teoria \& prática, Porto Alegre, v. 13, n. 1, p. 129139, jan./jun. 2010.

\section{Paula Patrícia Barbosa Ventura \\ Universidade Federal do Ceará}

\section{Introdução}

A complexidade do mundo contemporâneo tem modificado as relações sociais. As mídias atuais de comunicação (celular, computador, Internet, Ipod e muitas outras) têm evidenciado novas formas de interagir e estabelecer relações, seja de forma presencial ou virtual. A linguagem utilizada adapta-se ao meio em que os indivíduos estão inseridos e, por meio dela, substanciam-se as relações humanas (VENTURA, 2009).

Alguns estudos (SILVA, 2002, SÉRGIO, 2007) têm investigado as relações interpessoais que os indivíduos estabelecem nos ambientes virtuais, destacando os fatores que determinam os diferentes tipos de relações interpessoais quando fazem uso das Tecnologias de Informação e Comunicação (TIC). Entretanto, essa análise pode ser ampliada quando se pretende investigar não apenas os fatores que desencadeiam essas relações, mas os tipos de relações que aparecem em situações formais de ensino e aprendizagem, tais como: os momentos em que o professor explica o conteúdo, faz a mediação nos fóruns de conteúdo e bate-papos e quando os alunos apresentam trabalho em grupo.

Para tanto, esse estudo objetiva discutir as relações interpessoais em cursos a distân- 
cia, a partir dos resultados de uma pesquisa ${ }^{1}$ conduzida com alunos do curso de licenciatura semipresencial em Letras-Português, da Universidade Federal do Ceará, uma parceria com a Universidade Aberta do Brasil. A princípio, é proposto o conceito de relações interpessoais a partir da literatura específica. Ainda na mesma seção, discutem-se algumas habilidades sociais necessárias para o estabelecimento das relações humanas como tentativa de construir uma relação teórico-metodológica capaz de oferecer subsídios a algumas questões tratadas no decorrer desse artigo. Posteriormente, propõe-se o objeto de estudo e a metodologia do trabalho. Os resultados discutem quais os tipos de relações interpessoais foram efetivamente encontrados em situações de ensino-aprendizagem, como por exemplo, nas trocas comunicativas dos fóruns de discussão e bate-papos, nas explicações das professoras-tutoras e dos alunos entre si e em outros momentos detalhados neste artigo. Nas considerações finais, são apresentadas as contribuições do estudo para a compreensão do objeto analisado.

\section{Relações interpessoais: comunicação e habilidades sociais}

Oliveira (2007, p. 352) conceitua relação interpessoal como a "relação que se estabelece entre as pessoas, como consequência do contato". Para Antunes (2007, p. 9) seria um "conjunto de procedimentos que, facilitando a comunicação e as linguagens, estabelece laços sólidos nas relações humanas". Para tanto, pode-se considerar que é por meio do ato comunicacional que as relações acontecem. Essas relações não se dão no vazio e sim em determinados contextos; e, em situações específicas, podem se tornar mais evidentes, como nas trocas de pensamento, ideias e significados, pois a manifestação de diferentes relações interpessoais depende da dimensão pessoal (conhecimentos, sentimentos, crenças), e não somente da dimensão situacional (contexto onde ocorrem

1 A pesquisa é parte da dissertação de mestrado da autora desse artigo (VENTURA, 2009). Em especial, a autora agradece aos professores-orientadores José Aires de Castro Filho e Eduardo Santos Junqueira Rodrigues pelas contribuições ao longo da pesquisa. os encontros, status do interlocutor, presença ou ausência de outras pessoas, etc.) (PRETTE; PRETTE, 2007). Os autores enfatizam que a comunicação é essencial ao indivíduo e é entendida como um processo mediador do contato entre as pessoas.

Para Giddens (2005), a comunicação é a base necessária para toda interação social, o que implica entendimento e compreensão entre os indivíduos que se comunicam. Sánchez (1999) explicita que o ato de comunicar-se é sempre um ato voluntário e surge da vontade, da intenção de estabelecer contato com o outro. Dessa forma, a comunicação só se torna possível se os indivíduos estiverem dispostos e manifestarem interesse em suas ações, o que pode ser demonstrado por algumas habilidades sociais, como observar, ouvir e incentivar, por exemplo.

Segundo Echeverría (2003), quando se analisa detidamente a comunicação, se percebe que o essencial do ato comunicacional está em escutar e não apenas em falar, sendo aquele fundamental para a linguagem. O autor afirma:

Hablamos para ser escuchados. El hablar efectivo sólo se logra cuando es seguido de un escuchar efectivo. El escuchar valida el hablar. Es el escuchar, no el hablar, lo que confiere sentido a lo que decimos. Por lo tanto, el escuchar es lo que dirige todo o proceso de la comunicación ${ }^{2}$ (ECHEVERRÍA, 2003, p. 138).

Prette e Prette (2007) argumentam que a interação social requer muitas habilidades sociais, que são componentes da competência interpessoal necessária para o envolvimento em várias etapas de qualquer processo produtivo. Essas habilidades referem-se à capacidade de fazer e responder perguntas, elogiar, pedir e dar feedback, iniciar, manter e encerrar uma conversação, estabelecer relacionamento afetivo, expressar solidariedade, fazer amizades, lidar com críticas, dizer por favor, agradecer, apresentar-se, cumprimentar, despedir-se, manifestar opinião, desculpar-se e admitir falhas, consideradas habilidades essenciais em todo programa de treinamento de relações interpessoais. Para estes autores, dificilmente algum trabalho ocorre no isolamen-

2 Tradução da autora deste artigo: "Falamos para sermos ouvidos. O falar efetivo só é alcançado quando seguido por uma escuta eficaz. O escutar valida o falar. É o escutar e não o falar que confere sentido ao que dizemos. Portanto, o escutar é o que dirige todo o processo da comunicação". 
to social total. Por outro lado, existem alguns trabalhos cuja realização depende quase que inteiramente da relação com o outro, ou seja, da mediação das interações sociais.

Ao analisar as diversas habilidades propostas por Prette e Prette (2007), bem como as duas habilidades citadas por Echeverría (2003), verifica-se que o modo como os indivíduos se relacionam entre si depende das habilidades comunicacionais que cada um possui, por isso o ato comunicacional é fundamental nas relações sociais. Tais habilidades podem estar presentes nos trabalhos realizados em grupo, nas intervenções do professor, nas trocas propositivas entre os alunos, bem como em outros momentos que os indivíduos se encontrem. Tanto na Educação Presencial quanto na Educação a Distância via Internet, as habilidades sociais de comunicação interpessoal podem possuir componentes verbais e/ou simbólicos, como entonação de voz, expressões faciais e corporais, gestos que podem dar diferentes sentidos de interpretação em resposta a uma ação.

Na Educação a Distância via Internet, as habilidades sociais dos indivíduos são visualizadas através da linguagem escrita, pois a comunicação é predominantemente textual. Apesar disso, os participantes podem se valer de símbolos (emoticons) ou recursos tecnológicos como webcameras, microfones e outros, que estejam disponibilizados nos ambientes virtuais de aprendizagem (AVA).

Outro fator importante a ser mencionado sobre as habilidades sociais explicitadas por Prette e Prette (2007) é que elas não necessariamente implicam numa relação mais próxima com o outro. A proximidade referenciada aqui diz respeito a estar junto em pensamento e ideias, dando significado às interações virtuais, e não apenas à presença física. Essa proximidade pode estar relacionada às habilidades de demonstrar emoções positivas e negativas (alegria, raiva, desagrado, tristeza, respectivamente), expressar solidariedade, fazer amizades, pedir feedback, pedir desculpas e/ou admitir falhas e estabelecer relacionamento afetivo, que podem significar identificação com o outro, e o estabelecimento de relações mais duradouras.

Conforme abordam Prette e Prette (2007), as habilidades de demonstrar emoções são diferentes do estabelecimento de relacionamento afetivo, pois as emoções, assim como os desejos e sentimentos, são manifestações da vida afetiva. Para Oliveira (2007, p. 352), "as emoções que se criam em decorrência das relações interpessoais afetam de modo direto a natureza das interlocuções", sendo estas um processo de produção e troca de enunciados ${ }^{3}$ entre os interlocutores ${ }^{4}$.

Já a afetividade é um conceito mais abrangente, no qual se inserem várias manifestações que possuem relativa independência dos fatores corporais (GALVÃO, 1995). Por sua vez, as emoções possuem características que comumente estão associadas ao corpo, à postura e à forma como são executados os gestos, sendo muitas vezes visíveis ao outro.

Moran (1994, p. 5) enfatiza que o afetivo se manifesta pelo "clima de acolhimento, empatia, inclinação, desejo, gosto, paixão, ternura e compreensão para consigo mesmo, para com os outros e para com o objeto do conhecimento", dinamizando as interações, as trocas, a busca e os resultados.

Bauman (2004), ao tratar dos relacionamentos sociais, atribui significativa importância à afinidade entre os indivíduos. Para este sociólogo, a afinidade nasce da escolha e essa escolha deve ser reafirmada constantemente, caso contrário as relações vão murchando, uma vez que a escolha de estarem juntos deve ser por causa de e não a fim de, como enfatiza Bauman (2004) ao discutir a fragilidade dos laços humanos. Embora as relações sociais entre os indivíduos sejam construídas diariamente, elas precisam ser alimentadas, caso contrário, poderão vir a enfraquecer ou se desfazer com o tempo.

A amizade também é um tipo de relação interpessoal, segundo Prette e Prette (2007, p. $99)$, pois pode ser caracterizada pela "reciprocidade razoavelmente equilibrada de expressões de sentimentos positivos e negativos e de atitudes voltada ${ }^{5}$ para o bem-estar e a felicidade do outro". Essa relação se funda na transparência, em que os indivíduos se revelam como amigos confidentes, podendo se desenvolver naturalmente a partir de diferentes contextos de con-

3 Enunciado - "cada um dos segmentos discursivos gerados por um interlocutor" (OLIVEIRA, 2007, p. 348).

4 Interlocutor - "Apropriador dos elementos do discurso, enunciador, aquele que dá vida e sentido aos elementos discursivos; o autor/co-autor do contexto comunicativo onde o enunciado se insere" (OLIVEIRA, 2007, p. 350).

5 Ainda que a palavra esteja em desarcordo com a norma culta, por erro de concordância, se manteve a grafia original do texto citado. 
vivência ou ser uma relação buscada propositalmente junto a grupos específicos, como é o caso das comunidades virtuais de aprendizagem em cursos a distância.

Outro elemento importante nas relações interpessoais é mencionado por Prette e Prette (2007) quando afirmam que admitir erros ou falhas não é uma tarefa fácil, pois altera o autoconceito e a autoestima dos indivíduos, e que pedir desculpas significa reconhecer os "equívocos, desfazer mal-entendidos, diminuir ressentimentos e estabelecer a intenção de superar divergências" (PRETTE; PRETTE, 2007 , p. 78) nas relações sociais.

Em relação ao feedback, nas situações de aprendizagem é importante que o indivíduo reconheça suas atitudes em relação ao grupo e "perceba como se comporta e como esse comportamento afeta seu interlocutor" (PRETTE; PRETTE, 2007, p. 69).

Todas as habilidades sociais apontadas pelos autores são consideradas fundamentais nas CVA em cursos a distância, uma vez que os membros têm a possibilidade de se comunicar (in) formalmente e estender as relações a ambientes não-formais, como o Orkut e o MSN, por exemplo, demonstrando a necessidade de uma comunicação contínua, independente de ser uma exigência do curso.

Na próxima seção, serão apresentados os procedimentos metodológicos de investigação.

\section{Procedimentos metodológicos}

O estudo foi desenvolvido no semestre 2008/2, em uma turma de Graduação semipresencial em Letras-Português, da Universidade Federal do Ceará, realizado em parceria com a Universidade Aberta do Brasil. Participaram da pesquisa os 18 alunos regularmente matriculados no terceiro semestre do curso. A disciplina contou com uma carga horária de 64 horas (16 horas presenciais, distribuídas em quatro encontros e 48 horas, que aconteceram através do ambiente virtual de aprendizagem $\mathrm{SOLAR}^{6}$ ). A metodologia de pesquisa teve caráter predominantemente qualitativo sendo utilizado o método etnográfico (BOG-

6 Ambiente On-Line de Aprendizagem. Foi desenvolvido pelo Instituto UFC Virtual, da Universidade Federal do Ceará. Endereço eletrônico: www.solar.virtual.ufc.br
DAN; BIKLEN, 1994) e os princípios da etnografia virtual (HINE, 2004) na coleta e análise dos dados. Para a coleta de dados foram utilizadas entrevistas e observações presenciais e virtuais. As observações foram referentes às anotações do diário de campo, dois fóruns de discussão (os que tiveram o maior número de participações) e três bate-papos. O período de investigação correspondeu a duas disciplinas: Língua Portuguesa: Frase e Latim II: Língua e Cultura.

A partir da observação dos eventos (diário de campo, entrevistas, bate-papos e fóruns), elencaram-se as categorias de análise, com o intuito de construir diálogos e estabelecer relações entre os eventos e o referencial teórico, permitindo lidar com o campo complexo das trocas simbólicas e das interações. Em seguida, as categorias propostas foram agrupadas em categorias maiores. Nesta etapa, foi feita a triangulação dos dados (MOREIRA; CALEFFE, 2006), em que se estabeleceram as relações existentes entre os dados, verificando os pontos de convergência, divergência e regularidades. Por fim, buscou-se mapear os tipos de relações interpessoais estabelecidas na CVA analisada.

As relações interpessoais estão divididas em subcategorias e serão apresentadas em forma de eventos e tabelas. Os eventos podem ser referentes às anotações do diário de campo, às transcrições das entrevistas, mensagens dos fóruns ou dos bate-papos. As tabelas são apresentadas ao final para demonstrar a frequência de cada subcategoria. $O$ objetivo das tabelas foi mostrar que houve a presença de cada relação interpessoal de uma CVA em vários tipos de dados, tanto no ambiente presencial quanto no ambiente virtual. Os resultados são apresentados na próxima seção.

\section{Análise e discussão dos resultados}

Baseado nas ideias de Moran (1994), Silva (2002), Bauman (2004), Prette e Prette (2007), Echeverría (2003) e Antunes (2007), as relações interpessoais são conceituadas como as diferentes formas de relacionamento entre os participantes, que podem proporcionar vínculos positivos ou negativos e, através de sentimentos pessoais, os indivíduos mani- 
festam suas aceitações e rejeições em relação ao outro.

No ambiente presencial, as relações interpessoais apareceram quando os participantes recepcionavam os colegas quando chegavam no pólo; na proximidade física com os colegas; no incentivo; nas demonstrações de amizade e em confiar no outro ao assumir que não dominavam determinado conteúdo. As relações foram manifestadas através da linguagem formal e informal, dos gestos e das expressões faciais e corporais.

A linguagem formal foi percebida nos diálogos referentes ao conteúdo, nas respostas dos fóruns e em vários momentos dos batepapos, o que requereu um conhecimento prévio da norma culta para a comunicação entre os participantes. Já a linguagem informal foi caracterizada como uma linguagem improvisada utilizada nas conversas fora e dentro do contexto das aulas, em que não se fez uso da rigidez das normas gramaticais.

No ambiente virtual, as relações interpessoais apareceram na receptividade com os demais participantes nos bate-papos e fóruns de discussão; no incentivo; nas demonstrações de amizade; na informalidade ao se referir ao outro; e, em confiar no colega ao assumir que não dominava determinado conteúdo, acrescentando que no fórum os alunos argumentaram sentir medo de colocar uma resposta errada, pois o conteúdo era complicado e eles não tinham certeza que a resposta estaria correta, conforme é mostrado no evento a seguir: colegas, socorro! Quem já traduziu as frases 6,8,10 do portfólio 03? Tenho até medo de colocá-las aqui, pois sei que não estão corretas. Alguém já fez?7 (Evento 1 - Fórum de Discussão. Disciplina - Latim II: Língua e Cultura, 23/10/2008. Postado por Elza ${ }^{8}$ ).

Apesar das manifestações das relações interpessoais nos fóruns e bate-papos serem através da linguagem escrita, houve uma presença muito baixa do uso de emoticons, os quais geralmente são utilizados para suprir a ausência de expressões faciais e corporais (GOMES, 2004).

As relações interpessoais foram divididas em 4 subcategorias: amizade; incentivo, agra-

7 As respostas estão em itálico para diferenciar das citações.

8 Os nomes próprios que aparecem nesse artigo são fictícios, exceto o da pesquisadora (autora deste artigo). decimento e informalidade, as quais são explicitadas a seguir:

\section{a. Amizade}

Refere-se às manifestações emocionais que os participantes externalizaram aos sentimentos de falta, demonstrações de carinho, afinidade de gostos, receptividade e pedido de desculpas. A amizade foi caracterizada através de gestos, expressões faciais e corporais e em palavras na relação com o outro. As demonstrações de desapontamento para com o outro foram também atribuídas às relações de amizade, uma vez que as formas de expressar os sentimentos podem ser vistas como positivas ou negativas.

Para Prette e Prette (2007), a amizade se caracteriza pela reciprocidade de sentimentos positivos e negativos e de atitudes de bemestar e a felicidade do outro. As relações de amizades se fundam "na transparência, verificando-se o frequente exercício de revelarse ao amigo, tido como confidente" (PRETTE; PRETTE, 2007, p. 99), caracterizando interações colaborativas e não competitivas, estabelecendo críticas verdadeiras e trocadas de forma construtiva.

Na presencialidade, a amizade foi verificada na receptividade mútua, quando os alunos, à medida que chegavam à sala de aula, iam se cumprimentando com beijos; quando guardavam os lugares dos colegas, relatando que os amigos sentavam próximos uns dos outros e não se separavam; quando havia confidências dos colegas entre si, mostrando uma relação pautada na confiança e no diálogo; quando diziam para o colega que haviam sentido sua falta no dia anterior; quando os alunos durante e fora da aula externalizavam sentimentos de carinho, demonstrando envolvimento com os colegas; e quando se desculpavam por algum motivo.

Nas demonstrações de carinho foram utilizados gestos e expressões faciais e corporais, tipo: piscadelas, bilhetinhos e beijos durante a aula, mesmo que estivessem sentados distantes uns dos outros, e toques corporais quando estavam próximos. Na entrevista, uma das formas de amizade foi percebida quando a aluna relatou que se zangava com as colegas quando estava realizando trabalhos de grupo, porque havia alunos que se escoravam nos outros membros da equipe, esperando a atitude 
de alguém para se manifestar. A importância dada às ações do outro demonstrou um sentimento de preocupação e amizade, de sentir segurança no outro ao relatar seu desconforto na ausência de participação nos trabalhos de grupo, uma vez que as atitudes dos colegas de equipe eram sempre muito claras em relação ao outro. A seguir, um trecho que exemplifica o que é dito: Cada uma tenta fazer, aí no final a gente escolhe a ideia mais legal [...]. A gente colocava isso, porque tem sempre alguém que quer se encostar né e a gente num deixava, uma ficava vigiando a outra. (Evento 2 - Entrevista realizada com a aluna Bianca, no dia 10/11/2008).

Em relação ao ambiente virtual, a amizade foi vista quando os alunos demonstravam coletivamente sentimentos de solidariedade e cumplicidade para com os colegas. Nos fóruns, os alunos utilizavam expressões que se repetiam, como: amiga e minha amiga. Nos batepapos, à medida que os alunos iam entrando na sala, cumprimentavam-se, mesmo que as discussões já tivessem iniciado. Ao finalizar o bate-papo, apareceram expressões: beijos, beijoca em todos, um beijão para todos, mil beijos, um beijo, demonstrando não apenas um cumprimento para com o colega, mas uma despedida calorosa com a turma. Nos batepapos, foi frequente o pedido de desculpas, quando os alunos chegavam atrasados ou uma satisfação que era dada aos colegas quando precisavam sair; quando utilizavam palavras em maiúsculo no meio de palavras em minúsculo explicando que a intenção não era gritar ${ }^{9}$ e sim fora um erro na escrita; e quando se equivocavam numa opinião dada ao colega.

Nos eventos que seguem, têm-se dois exemplos de amizade:

Evento 3 (Diário de campo. Disciplina: Latim II: Língua e Cultura, 07/10/2008):

Uma aluna que havia chegado atrasada foi até o computador de cada colega cumprimentá-los. $\mathrm{Tal}$ aluna percebeu que uma das colegas que estava em um dos computadores havia faltado no dia anterior, e disse a ela: "eu senti sua falta, viu".

Evento 4 (Entrevista realizada no dia 10/11/2008).

Paula Patrícia: Faz amizades na turma, que possibilitam outros tipos de relação?

9 De acordo com a Netiqueta (regras para quem utiliza a Internet), escrever com letras maiúsculas significa gritar com o outro (COMO..., 2006).
Bianca: Sim (...). Mas às vezes eu marco um chat com as meninas. Pessoal vamu lá pro chat conversar e aí a gente entra.

...

Bianca: (...) quando bate a saudade aí eu ligo. Vixi pessoal cadê, todo mundo sumiu. Que é isso? (...). Aí eu começo a perturbar o pessoal, boto mesmo mensagem mesmo lá. O curso permite a gente de férias, eu botando mensagem lá. Ei pessoal (riu).

No evento 3, a amizade pode ser visualizada pelo sentimento de ausência, o que demonstra amizade e carinho pela colega. No evento 4, primeiro a aluna demonstrou sentir falta da turma, marcando uma sessão de bate-papo com as amigas. Segundo, mesmo os colegas estando de férias, a aluna Ihes enviou uma mensagem informal. Conforme os dois exemplos, a amizade foi vista em diferentes momentos (formais e informais), revelando que esta categoria não ocorreu num único tipo de momento.

\section{b. Informalidade}

Refere-se às formas de tratamento entre os participantes ou a maneira de agir em determinadas situações. A informalidade esteve relacionada tanto em momentos de trocas comunicativas em sala de aula quanto em momentos extraclasse e foram percebidas pela linguagem, oral e escrita, descritas em cada ambiente.

No ambiente presencial, a informalidade foi visualizada quando os alunos se reportavam às colegas com seus nomes abreviados e no diminutivo; quando diziam um palavrão ao conversarem ou perguntarem algo; por tirarem uma brincadeira na aula com o colega e por contarem piadas na hora da explicação, levando a situações de descontração e diminuindo os momentos de seriedade entre os participantes. Na entrevista, uma aluna se reportou à colega, à turma ou à situação, respectivamente, como mocinha, novinha, ai mulher, pessoal, meninas, colegas, gente, tá legal, vixi.

No ambiente virtual, a informalidade foi visualizada no fórum pela forma de um aluno se reportar ao outro, por exemplo: turma, colegas, coleguinhas, meninas, olá, gente; ou em resposta a algum questionamento ou mensagem de complementação ou explicação, tipo: legal, valeu. Nos bate-papos, as formas de tratamento e de responder aos colegas foram: colegas, meninas, gente; olá, turma, pessoal, gatinha, galera, oi, ops, ora, legal viu, oh, ufa 
e vixi. Tanto nos fóruns como nos bate-papos, os alunos se reportavam aos colegas com nomes abreviados, o que demonstrou formas de tratamentos informais.

A informalidade nos bate-papos pode ser considerada como algo que já era esperado, uma vez que as ferramentas síncronas possibilitam uma linguagem mais próxima da fala oralizada dos participantes, porque eles sentem que podem se expressar livremente por estarem em contato simultâneo com o colega, e, ao mesmo tempo, receberem uma resposta ao que foi enviado. Segundo Oliveira (2007), o bate-papo é um mix de fala e escrita, de discurso verbal e não-verbal havendo resgate da espontaneidade, aproximando os interlocutores da troca diádica ${ }^{10}$ e criando a impressão de maior intimidade.

Santos (2005, p. 175) enfatiza que "a linguagem dos chats faz uso de gírias, nasce do uso da associação com os sons da fala, muda conforme muda a fala, $[\ldots .$.$] ". Ou seja:$

Em um chat o erro estaria em se escrever afinado demais com as normas gramaticais. A necessidade de velocidade, de irreverência, de construção de um estilo próprio e da constituição de um grupo determina a norma desse gênero. E a norma é: cortar palavras, usar abreviaturas, emoticons, onomatopéias, gírias e pontuação expressiva procurando todos os recursos capazes de tornar a comunicação algo bem informal (SANTOS, 2005, p. 177).

Para tanto, a informalidade no ambiente virtual se expressa através de uma linguagem que pode ser considerada híbrida, a qual possui traços da linguagem oral e traços da linguagem escrita. A seguir, se exemplifica a categoria informalidade:

Evento 5 (Chat 1 - turma B. Tema: Variação Lingüística. Disciplina: Língua Portuguesa-Frase, 23/09/2008):

L.1 ALDA fala para TODOS:

L.2 Valha !!! O peixe engoliu a Laura :))

[...]

L.3 ALDA fala para TODOS:

L.4 Brincadeirinha..só para passar o tempo!

L.5 LAURA fala para TODOS:

L.6 Não Alda eu ainda vou colocar a minha foto

L.7 LAURA fala para TODOS:

L.8 meninas calma vou colocar a foto.

L.9 ALDA fala para TODOS:

10 "Interação face a face entre interlocutores, seja presencialmente ou por ferramenta de comunicação síncrona com imagem e som" (OLIVEIRA, 2007, p. 353).
L.10 Pode deixar!!! Eu vou ficar com a gorduchinha por algum tempo. Ela tem uma carinha mais simpática do que a minha.

O evento 5 demonstra a presença de informalidade, pois os alunos estavam iniciando uma sessão de bate-papo quando uma aluna pediu para a colega colocar uma foto sua, pois no momento a aluna possuía uma imagem de peixe, uma vez que o ambiente virtual de aprendizagem SOLAR, disponibiliza de imagens de animais, da natureza e de miscelânea ${ }^{11}$. Nesse caso, o aluno pode escolher qualquer imagem caso não tenha uma foto própria, por isso a aluna estava sendo representada pela imagem de um peixe, e a colega pela imagem de uma boneca gorda. A conversa também possuiu um emoticon no início, o que deu outro tom de informalidade.

Abaixo, observa-se outro exemplo de informalidade:

Evento 6 (Diário de campo. Disciplina: Língua Portuguesa-Frase, 16/09/2008):

Os alunos estavam em círculo corrigindo a atividade impressa e o celular de Lucas tocou. Por sua vez, ele estava sentado de frente à professora e olhando pra ela, falou rindo e em voz alta: estou em aula e a professora é muito chata, o que foi motivo de brincadeira por todos.

No evento 6, a ação do aluno ao falar ao telefone exemplifica uma situação informal. Mesmo que todos estivessem num momento de discussão e aprendizado, o aluno tira uma brincadeira para descontrair a turma e até mesmo a professora-tutora. Pelo sorriso dos alunos e a expressão facial de Lucas, ficou demonstrado que aquela situação não passava de uma brincadeira, uma vez que Lucas era tido, pelos colegas, como o aluno mais extrovertido e brincalhão. Ele continuou a descontrair a turma em outros momentos da aula, pois os exemplos que dava para responder as questões demonstravam seu senso de humor e espontaneidade mesmo em momentos formais.

Em momentos informais, não eram apenas os alunos que se distraíam entre si, mas as professoras-tutoras também, uma vez que as brincadeiras não atrapalhavam totalmente 0 andamento da aula, pois os alunos tinham consciência dos seus papéis ${ }^{12}$ (VENTURA, 2009).

\footnotetext{
11 Essa denominação é do próprio ambiente e significa "Imagens Variadas".

12 Outras categorias foram elencadas na presente pesquisa,
} 
Na relação entre as professoras-tutoras e alunos, a informalidade apareceu quando os alunos faziam gracejos com elas durante a explicação do conteúdo, no início ou intervalo das aulas. Especificamente com a professora-tutora da disciplina de Língua Portuguesa: Frase, a informalidade também apareceu nos bate-papos ao iniciar a seção ou ao final, na despedida utilizando onomatopeias, emoticons, letras maiúsculas e pontuação expressiva, e quando se referia as alunas por meninas, demonstrando um tom informal, o que também foi caracterizado como o papel social da professora-tutora mais detalhado na categoria papel do professor-tutor.

\section{c. Incentivo}

$O$ incentivo refere-se às formas de incentivar, apoiar e confortar o outro em suas necessidades. Para Prette e Prette (2007), as ações de apoio se relacionam com a empatia, que significa "a capacidade de compreender e sentir o que alguém pensa e sente em uma determinada situação" (PRETTE; PRETTE, 2007, p. 86). Segundo os autores, a comunicação empática gera disposição de partilhar dificuldades ou êxitos, estabelecendo ou fortalecendo vínculos de amizade e cria ou intensifica um canal de comunicação entre os indivíduos.

De acordo com os dados da pesquisa, apareceram duas formas de incentivo: individual e coletivo.

No ambiente presencial, o incentivo apareceu diversas vezes, dentre elas: quando uma aluna incentivou o colega para não desistir no curso, pois o aluno havia relatado que trabalhava os três turnos e ainda precisava ser liberado da escola onde trabalhava para frequentar as aulas do curso. Outro exemplo diz respeito às anotações do diário de campo, quando o mesmo aluno relatou que seu sucesso em uma das disciplinas anteriores se deu ao incentivo da colega.

No ambiente virtual, o incentivo foi visualizado quando os alunos estavam discutindo no fórum de discussão e alguns alunos estimulavam as respostas colocadas pelos colegas, como é mostrado a seguir: É tentando que se consegue. Se tiver errado, nós tentaremos $\operatorname{acerta}^{13}$, não é? (Evento 7 - Fórum de Discussão. Disciplina - Latim II: Língua e Cultura, 23/10/2008. Postado por Sofia).

No bate-papo, o incentivo surgiu quando uma aluna estimulou os colegas a participarem da discussão e também quando uma aluna falou para todos sobre seu desejo de que todos conseguissem postar a atividade de portfólio no dia estipulado pela professora-tutora de Língua Portuguesa: Frase. Como foi visto nas duas ferramentas do ambiente virtual utilizado, fórum e chat, o incentivo não ocorreu apenas de forma individual, como mostram os dois eventos a seguir:

Evento 8 (Diário de campo. Disciplina: Língua Portuguesa-Frase, 15/09/2008):

Duas alunas conversando no intervalo e uma perguntou pra outra o porquê dela estar triste. Essa aluna respondeu que não havia saído o resultado de uma das disciplinas anteriores e caso ela não tivesse sido aprovada não poderia cursar a disciplina atual com a sua turma, pois teria que repetir aquela disciplina com outra turma. A colega que estava a ouvir, disse: "mas vai dar certo".

Pela descrição do evento 8, o incentivo foi de forma individual e, com uma frase apenas, todo um contexto foi modificado, uma vez que a aluna mostrava-se triste e calada, mas ao conversar e dizer o que estava sentindo, que temia não continuar com os amigos da sua turma, começou a conversar com os colegas que estavam a sua volta, mesmo que de forma tímida.

$\mathrm{Na}$ relação entre as professoras-tutoras e alunos, o incentivo foi o de participarem das discussões, enfatizando que eles eram capazes, e o de parabenizar pelas colocações expostas nos bate-papos e fóruns, o que motivou a novas participações.

Nos dados encontrados, verificou-se que algumas vezes foram os próprios alunos que se incentivaram entre si. $O$ incentivo surgiu não apenas quando os alunos se sentiam desencorajados ou quando estavam com algum problema, mas na espontaneidade na resolução das atividades e nos intervalos das aulas. As atitudes de incentivo entre os alunos foram fundamentais para o desenvolvimento da au- 
tonomia, pois os alunos tinham a iniciativa de iniciar as discussões e de promover o debate, pois esperar apenas pelas professoras-tutoras os levaria ao erro de focalizá-las como as únicas pessoas ativas da relação professor-aluno. Ativas no sentido de tomar a frente das discussões, das opiniões e das trocas entre os participantes. O incentivo não deve ser apenas atribuição do docente ${ }^{14}$, pois o aluno pode criar rótulos ao achar que é só o professor quem deve estimular, caminhar junto, fornecer ajuda ao aluno e outras atribuições que comumente lhe são designadas.

No evento a seguir, o incentivo é apresentado de forma coletiva:

Evento 9 (Fórum de Discussão. Tema: $4^{a}$ e $5^{a}$ declinações. Disciplina: Latim II: Língua e Cultura, 21/10/2008):

Telma [aluna]

Turma, nunca pensei que Latim fosse tão complicado. (...) Mas... coragem, força de vontade e as explicações das colegas chegaremos lá.Espero. (...)

A relação de incentivo que Telma estabeleceu no fórum não foi apenas a um aluno em específico, mas à turma toda, pois os alunos estavam com muitas dúvidas acerca do trabaIho a ser entregue (a tradução de vinte frases da língua latina para a língua portuguesa). 0 referido fórum foi para tirar dúvidas dos alunos acerca desse trabalho, e o trecho coragem, força de vontade e as explicações das colegas chegaremos lá demonstrou que mesmo com as dificuldades a colega acreditava nos companheiros, levando-a a incentivar com palavras de estímulo e ânimo.

\section{d. Agradecimento}

Referem-se às formas de expressar gratidão às ações dos demais participantes. Para Prette e Prette (2007), gratificar tem sido considerada uma competência tradicionalmente associada a pessoas carismáticas, populares e líderes, uma vez que é um ingrediente relevante nas relações sociais satisfatórias e equilibradas. Relações satisfatórias e equilibradas são aquelas em que há escuta, atenção e feedback às ações que são realizadas por um indivíduo, não ficando a responsabilidade

14 Conforme a nota de rodapé anterior, a categoria Papéis foi elencada como parte dos dados da pesquisa. O incentivo foi categorizado tanto como papel do aluno quanto do professor. Para uma melhor compreensão, ler a íntegra da dissertação (VENTURA, 2009). da relação apenas por parte de uma pessoa. Segundo Echeverría (2003), agradecer não é apenas dizer obrigado, é construir uma relação com o outro. Para o autor, quando se agradece "no solo asumimos uma postura 'frente' a los otros y 'frente' a la vida. Al hacerlo, participamos en la generación de nuestras relaciones con ellos y en la de la propia construcción de nuestra vida" (ECHEVERRÍA, 2003, p. 82) ${ }^{15}$.

No ambiente presencial, as formas de agradecimento estiveram relacionadas à ajuda e aos favores que os alunos faziam uns aos outros, como: explicar o conteúdo; emprestar material; ceder à cadeira ao colega e as caronas que os alunos davam entre si. As ações de agradecimento foram das mais elementares, desde ceder o lugar ao colega, até ações mais complexas, como explicar o conteúdo. Todas as formas de prestar atendimento ao colega eram gratificadas, conforme apresentado nos dados da pesquisa.

No ambiente virtual, o agradecimento pôde ser visualizado quando os alunos se ajudavam entre si, no fórum: fornecendo feedback; tirando dúvidas ou complementando as mensagens dos colegas. No bate-papo, quando alguns alunos chegavam atrasados e os colegas que já estavam on-line cumprimentavam desejando boas vindas; ou quando repetiam alguma colocação importante da professoratutora que havia passado despercebida, e, ao final do bate-papo, quando a aluna agradeceu à turma pelos esclarecimentos na resolução dos exercícios; quando os alunos agradeceram aos colegas e a professora-tutora por terem gostado da discussão e pela contribuição em seu aprendizado.

Evento 10 (Fórum de Discussão. Tema: $4^{a}$ e $5^{a}$ declinações. Disciplina: Latim II: Língua e Cultura, 22/10/2008):

Raísa [aluna]

Obrigada Marta valeu muito.Gostaria de agradecer e parabenizar os colegas pela interação e colaboração como a Alda coloca e muito bem: "nada mais é do que crescimento e colaboração", continuem sempre com essa postura, acima de tudo, humana.

No evento 10, Raísa não apenas agradeceu, mas parabenizou Marta por outras atitudes

15 Tradução da autora deste artigo: "Não somente assumimos uma postura frente aos outros e frente a vida. Ao fazer isso, participamos da geração de nossas relações com eles e na construção da nossa própria vida". 
que esta estava demonstrando durante todos os questionamentos, dentre eles o de dominar o conteúdo. Esse agradecimento, assim como outros no fórum, foi de agradecimento às colocações sempre precisas de Marta.

Na relação entre professoras-tutoras e alunos, o agradecimento apareceu em diversas ocasiões: quando os alunos agradeciam à participação e discussões de todos; quando agradeciam à receptividade da professora-tutora, da disciplina de Língua Portuguesa: Frase, nas seções de bate-papo, pois mesmo tendo começado a aula, ela sempre recepcionava o aluno que estava entrando na discussão; quando uma aluna agradeceu também por ela prorrogar o prazo das atividades; quando agradeceu pelo modo de correção dos trabalhos individuais, uma vez que ela corrigia fazendo alterações no próprio documento e quando enviou um arquivo aos alunos por e-mail com orientações de como realizar as atividades. As ações de agradecimento dos alunos para com duas professoras-tutoras aconteceram pela ferramenta fórum e chat.

A seguir, segue a frequência de cada subcategoria das relações interpessoais entre os alunos:

TABELA 1 - Frequência da Subcategoria - Relações Interpessoais Entre Alunos

\begin{tabular}{|l|c|c|c|c|}
\hline $\begin{array}{l}\text { Relações } \\
\text { Interpessoais }\end{array}$ & $\begin{array}{c}\text { Diário } \\
\text { de } \\
\text { Campo }\end{array}$ & $\begin{array}{c}\text { Entre- } \\
\text { vistas }\end{array}$ & Fóruns & $\begin{array}{c}\text { Bate- } \\
\text { papos }\end{array}$ \\
\hline Amizade & 16 & 11 & 3 & 21 \\
\hline Informalidade & 24 & 27 & 33 & 93 \\
\hline Incentivo & 3 & 1 & 8 & 6 \\
\hline Agradecimento & 1 & 0 & 11 & 12 \\
\hline
\end{tabular}

Conforme os dados da Tabela 1, o agradecimento foi a subcategoria que apresentou a menor frequência no diário de campo e a ausência de ocorrência nas entrevistas. Nas entrevistas, há apenas uma ocorrência na subcategoria incentivo, quando Bianca relatou que usava indevidamente a ferramenta fórum para incentivar os colegas, e que recebia alguns puxões de orelha por postar algumas coisas para a turma, pois às vezes achava o curso meio frio porque queria dizer uma coisa engraçada quando alguém respondia de forma séria, como é mostrado no evento a seguir:

Evento 11 (Trecho da Entrevista realizada com a aluna Bianca, no dia 10/11/2008).

Esse curso às vezes é meio frio né, porque às vezes a gente quer dizer uma coisa engraçada e, às vezes a pessoa pode achar que a gente tá né questionando alguma coisa, dando piada, aí às vezes a pessoa responde de uma forma, valha não foi bem assim, eu acho que eu não soube me expressar.

Nos fóruns, o menor índice foi na subcategoria amizade, pois conforme o relato de Bianca, os alunos deviam se atentar para o que era dito no fórum, embora aparecessem mensagens de Incentivo, Agradecimento e de Informalidade. A frequência que mais se destaca é a da Informalidade, o que evidencia o caráter informal entre os alunos em momentos formais de ensino e aprendizagem, como os diálogos entre os discentes e as docentes. Ainda que as discussões se voltassem ao conteúdo, as mensagens tinham caráter informal, o que não descaracterizou as mensagens ditas formais.

A seguir, apresenta-se a frequência de cada subcategoria das relações interpessoais entre professoras-tutoras e alunos:

TABELA 2 - Frequência da Subcategoria - Relações Interpessoais: Professor-Tutor e Alunos

\begin{tabular}{|l|c|c|c|c|}
\hline $\begin{array}{l}\text { Relações } \\
\text { Interpessoais }\end{array}$ & $\begin{array}{c}\text { Diário } \\
\text { de } \\
\text { Campo }\end{array}$ & $\begin{array}{c}\text { Entre- } \\
\text { vistas }\end{array}$ & Fóruns & $\begin{array}{c}\text { Bate- } \\
\text { papos }\end{array}$ \\
\hline Amizade & 0 & - & 0 & 0 \\
\hline Informalidade & 2 & - & 0 & 7 \\
\hline Incentivo & 1 & - & 7 & 68 \\
\hline Agradecimento & 0 & - & 2 & 17 \\
\hline
\end{tabular}

De acordo com os dados da Tabela 2, as relações entre professoras-tutoras e alunos mais evidentes foram no ambiente virtual. As ações de incentivar nos bate-papos foram fundamentais, uma vez que a professora-tutora havia relatado que os alunos estavam com dificuldade no conteúdo, o que foi explicitado em detalhes na categoria Papéis do professortutor. Portanto, suas ações de incentivar e enfatizar que os alunos eram capazes contribuíram para que as participações aumentassem. As formas de agradecimento eram um retorno que os alunos forneciam as professoras-tutoras, pois ao agradecerem relatavam a postura positiva de cada uma delas para com eles. 


\section{Considerações finais}

Os dados evidenciam a importância das relações interpessoais nos processos de aprendizagem, sejam eles presenciais ou virtuais. Comprovou-se que o uso do espaço virtual não interferiu nos tipos de relações, permitindo que os alunos utilizassem uma multiplicidade de deixas simbólicas para o ato comunicacional.

Considera-se também que as relações interpessoais nos ambientes formais de ensino e aprendizagem devem se valer de habilidades comunicacionais voltadas não apenas ao lado intelectual, mas ao lado social e pessoal, como a capacidade de ouvir as necessidades do outro, apoiar, respeitar as diferenças do outro e se perceber como sujeito nas trocas compar- tilhadas, dentre outras fundamentais para que se dê a interação e consequentemente às formas diferenciadas de relacionamento.

Os dados atestaram ainda uma forte presença dos encontros presenciais para o fortalecimento das relações interpessoais, indicando que essas não aconteceram de forma separada (só interações presenciais e só interações virtuais), e sim foram complementadas quando iniciadas no ambiente presencial. Daí a importância de se considerar todos os momentos de encontros entre os participantes, pois presencial e virtual não podem ser vistos como contextos separados e isolados, mas complementares e interdependentes. Dessa forma, pode-se pensar numa continuidade de relações, sejam elas formais ou informais, e que essas podem sofrer modificações com o tempo e a intensidade das interações.

\section{Referências}

ANTUNES, C. Relações Interpessoais e Auto-estima: a sala de aula como espaço do crescimento integral. 5. ed. Petrópolis, RJ: Vozes, 2007.

BAUMAN, Z. Amor Líquido: sobre a fragilidade dos laços humanos. Rio de Janeiro: Jorge Zahar, 2004.

BOGDAN, R.C.; BIKLEN, S.K. Investigação Qualitativa em Educação: uma introdução à teoria e aos métodos. Porto: Porto Ed., 1994.

COMO Usar e Gerenciar Seus E-mails. CADERNOS ELETRÔNICOS, São Paulo, n. 1, 2006. Disponível em: <http://www.acessasp.sp.gov.br/cadernos/todos_cadernos.php> Acesso em: 21 set. 2009.

ECHEVERRÍA, R. Ontología del lenguaje. 6. ed. Santiago do Chile: Dólmen, 2003.

GALVÃO, I. Henri Wallon: uma concepção dialética do desenvolvimento infantil. Petrópolis, RJ: Vozes, 1995.

GIDDENS, A. Sociologia. 4. ed. Porto Alegre: Artmed, 2005.

GOMEZ, M.V. Educação em Rede: uma visão emancipadora. São Paulo: Cortez: 2004.

HINE, C. Etnografia Virtual. Barcelona: Ed. Luoc, 2004.

MORAN, J.M. Interferências dos Meios de Comunicação no Nosso Conhecimento. Revista INTERCOM: revista brasileira de comunicação, São Paulo, v. 17, n. 2, jul./dez. 1994. Disponível em: <http://www.eca.usp.br/ prof/moran/interf.htm>. Acesso em: 21 set. 2009.

MOReIRA, H.; CALEFfE, L.G. Metodologia da Pesquisa Para o Professor Pesquisador. Rio de Janeiro: DP\&A, 2006. 
OLIVEIRA, S.C. A Interlocução na Graduação a Distância: processo, ferramenta e resultado em transição paradigmática. 2007. Tese (Doutorado em Informática na Educação) - Faculdade de Educação, Universidade Federal do Rio Grande do Sul, 2007, Porto Alegre, BR-RS.

PRETTE, A.D; PRETTE, Z.A.P.D. Psicologia das Relações Interpessoais: vivências para o trabalho em grupo. 6. ed. Petrópolis, RJ: Vozes, 2007.

SÁNCHEZ, F.M. Os Meios de Comunicação e a Sociedade. In: MEDIATAMENTE!: televisão, cultura e educação. Brasília: Ministério da Educação, SEED, 1999.

SANTOS, E.M.S. Chat: e agor@?: novas regras, nova escrita. In: COSCARELLI, C.V; RIBEIRO, A.E. (Org.). Letramento Digital: aspectos sociais e possibilidades pedagógicas. Belo Horizonte: Ceale, Autêntica, 2005. P. 151-183.

SÉRGIO, J.S.R.L. Presença Social, Percepções, Relações Interpessoais e Grau de Satisfação com o Curso de E-Learning. 2007. Dissertação (Mestrado) - Universidade Aberta, 2007, Porto.

SILVA, A.M.P. da. Mundos Reais, Mundos Virtuais: as relações interpessoais na (em) rede. 2002. Dissertação (Mestrado) - Universidade Aberta, 2002, Porto.

VENTURA, P.P.B. Comunidades de Aprendizagem em Cursos a Distância: investigando as relações sociais em ambientes virtuais. 2009. Dissertação (Mestrado) - Programa de Pós-Graduação em Educação, Universidade Federal do Ceará, 2009, Fortaleza, BR-CE. Disponível em: http://www.tede.ufc.br/tde_busca/processaPesquisa.php?pesqExecutada=1\&id=2686. Acesso em: 02 abr. 2011.

Recebido em novembro de 2009.

Aprovado para publicação em setembro de 2010.

\section{Paula Patrícia Barbosa Ventura}

Mestre em Educação, com ênfase em Tecnologias Digitais na Educação pela Universidade Federal do Ceará (UFC). Especialista em Informática Educativa (UFC) e Graduada em Pedagogia (UFC) - Fortaleza-CE/Brasil.

Email: paula@virtual.ufc.br 